\title{
Group Competition and Personality in an Experimental Public Goods Game
}

\author{
Junyang Zhang ${ }^{1}$ \\ ${ }^{1}$ The High School Affiliated to Renmin University of China, Beijing, China
}

\begin{abstract}
Based on an experiment in Japan in 2008, this paper explores a new dimension of thinking. This paper introduces a variant form of public goods game, that is, ten participants compete for awards. It uses experimentation to consider behavioral and personality aspects, enabling us to explore new areas. In terms of behavior, awareness within and between groups is effective rather than a climate of non cooperation. In the aspect of personality, this paper studies the game from four aspects: preference for competition, preference for risk, enthusiasm for profit and trust in others. In a word, in a collective: the more people think about themselves, the less cooperative they are, and in most cases, they will not make profits; the more people who consider the collective, the more likely they are to cooperate, and in most cases, the higher their profits.
\end{abstract}

\section{INTRODUCTION}

Public goods have two different levels: non-uniqueness and non-competitive consumption. "Non-deceptive" means that the cost of preventing non-payers from enjoying the profit of the product or service is too high. For example, if entrepreneurs start a firework show, everyone can watch the show from the window or courtyard. Because entrepreneurs cannot deduct consumption expenses, even if the requirements for fireworks are abundant, fireworks displays may not be able to be produced.

The pyrotechnic example illustrates the related free-riding problem. Even if the fireworks show is all ten dollars for everyone, it can be said that very few people will pay ten dollars to entrepreneurs. Everyone will allow others to pay for the show and then watch it online for free from his or her yard in search of a "hitchhiking." If the free-riding problem cannot be dealt with, then products and services with use value (otherwise people want to pay for it) will not be manufactured.

The second level of public goods is the "extraordinary consumption" that economists have put in plain terms. Assume that entrepreneurs find ways to eliminate non-promoters from watching performances (perhaps only in personal venues to watch performances). A certain price will be deducted when entering the wilderness, and those who refuse to pay the price will be cleared out. However, if the field name is sufficiently large, the removal efficiency is very low. Even non-paying customers can still watch the variety show without increasing the cost of the variety show or reducing the enjoyment of others. In other words, the related consumption is unparalleled. However, in the two levels of public goods, non-exclusiveness is generally regarded as crucial. If the product is unique, the individual entrepreneur will try to serve as many customers as possible, and deduct lower prices from some customers when necessary.

National defense security is one of the best examples of public goods. In a sense, people in a geographic area can be protected from attack or intrusion by outsiders, while others in the same area are also likely to suffer defensive power. This makes it impossible for everyone to defend national defense security, which represents the classic free-riding problem encountered by national defense security. Indeed, almost all economists feel that the only way to show a sufficient level of defensive power is to let government agencies do that, and use taxes to show assets as defensive power.

However, many other problems are generally regarded as not public product problems. In fact, they are not real problems. The sales market can effectively solve them. For example, although many people think that satellite signals are a public product, cable digital TV service projects disrupt their transmission, making it impossible for non-subscribers to easily receive broadcast programs. In other words, the operator has already figured out how to eliminate non-paying parties. In all history and today, personal roads are all supported by highway fees deducted from road users. Other products that are generally regarded as public products, such as personal maintenance and fire safety service items, are often sold by individual units according to charging standards. It is very possible to clear the non-payer. In other situations, potential public goods are supported by advertising, just like televisions and radio programs.

Some public products can also be connected with the 
purchase of personal products, so that all packaging is more like personal products. For example, large and medium-sized shopping malls provide consumers with various services that are traditionally regarded as public welfare: such as lighting fixtures, safety protection services, rows of chairs and toilets. Immediately charging for each of these service items is out of practice. Therefore, the shopping mall displays assets for service items based on the proceeds from the sale of personal items in the shopping mall. Public and personal items are "tied" together. Individual apartment buildings and retired communities are also sales and marketing organizations that connect public products and personal service items. They use monthly membership fees to show various public cultural services.

Some public products are produced on the basis of reputation encouragement or subjective factors of the person who does a good job. The Internet presents millions of homepages and content websites, and most of them

The agent's voluntary cooperation is very important in the real economy, because many contracts are incomplete and effective behaviors cannot be formally implemented. In addition, many real-world issues require cooperation in the context of free riding incentives. Based on the standard hypothesis, the Nash equilibrium involving cooperative decision-making game is inefficient. In order to find an effective way to do a better job in a company with free riders everywhere, the author wrote this article and studied the variation of a three round commodity game to understand how to produce inefficiency.

\section{LITERATURE REVIEW}

Marwell and Ames introduced a kind of public goods game, in which they have resources that can be allocated, whether it is their personal consumption or the public consumption of the crowd[3]. In their experiments, the tokens they use are always more useful for themselves and can be consumed, but when the entire population is used to produce public products, their use value is higher. Many public product game experiments show that the collaboration between people far exceeds the scope of predictive analysis of normative economic theory, which assumes that one is objective and selfish. However, another objective fact is that the payment to the group account is far less than the $100 \%$ Pareto optimal level, and there is a very large heteroscedasticity in my payment selection. The article analyzes the personality traits of the contestants to study the latter situation.

Some theoretical charity games will introduce gifts in detail. Baik clearly proposed a team public benefit award, which is a public product within the team. The article stated that the local government has a budget for the construction of bridges, and many communities are vying to obtain the budget. The local government selected Shengli Community according to the criteria of agreeing donors. The gifts in every model are public welfare gifts for special groups.

\section{DESIGN \& INTRODUCTION OF THE GAME}

The rules of the game are very simple. Each student has ten yuan of money and two different accounts. They need to decide how to allocate the money. If people invest in a private account, all the money invested will remain in their own name, but there will be no additional income. If people invest in a public account, they will get three yuan for every yuan they invest, but the public account is shared by all people, and the money in its needs to be shared equally with all people. There are three rounds of the game. After each round, the author will calculate the results of the previous round with a table.

In this game, the ideal situation is that each participant of 10 people will invest all their money in the public account, and there will be 100 in the public account, which will be tripled to 300 , and the average will be distributed to 10 people. Then each person will finally have 30 yuan of wealth. If one of them doesn't invest and puts all his money into his private account, he can get 10 yuan from the private account, plus one tenth of 270 yuan in the public account, and finally 37 yuan. If someone doesn't invest in any cost, he will get a higher return.

It is easy to see that the Nash equilibrium in this game is that no one invests in public accounts and does not create any wealth. The payoff function mentioned above is as follows:

$$
\mathrm{yi}=\mathrm{Ei}-\mathrm{Ci}+(\mathrm{mpcr}) *\left(\sum \mathrm{Cj}\right)
$$

The amount of the public good of a group is supplied by the sum of all contributions $\mathrm{Ci}$ made to it by its members. The theoretical game prediction is complete free riding by all subjects.

\section{THE PROCESS AND ANALYSIS OF THE GAME}

\subsection{The First Round}

In the first round as table 1 shows, there was 20.1 yuan in the public account, and after three times it was 60.3 yuan, so each participant (13 participants) could get 4.6 yuan from the public account. We can see that most of the participants in the first round of the game are willing to invest in public accounts, but five of them decided not to invest in the first round and enjoy the fruits of other people's labor.

\subsection{The Second Round}

The author and participants made a deal in which everyone has to invest in public accounts together. The results of the third round are as follows.

As table 2 shows, there are only 11 yuan in the public account, which is half of the previous round. What surprises the author is that only one more participant chose to invest 0 yuan this time. Other investors in the last round only reduced the investment amount and did not completely lose confidence in others. 
TABLE 1. The First Round OF THE GAME[1]

\begin{tabular}{|c|c|c|c|c|}
\hline Round 1 & Code name & Private & Public & Income \\
\hline 1 & A & 8 & 2 & 12.63846 \\
\hline 2 & B & 7 & 3 & 11.63846 \\
\hline 3 & C & 7 & 3 & 11.63846 \\
\hline 4 & D & 10 & 0 & 14.63846 \\
\hline 5 & E & 10 & 0 & 14.63846 \\
\hline 6 & F & 7 & 3 & 11.63846 \\
\hline 7 & G & 9 & 1 & 13.63846 \\
\hline 8 & H & 9 & 1 & 13.63846 \\
\hline 9 & I & 9.9 & 0.1 & 14.53846 \\
\hline 10 & J & 10 & 0 & 14.63846 \\
\hline 11 & K & 10 & 0 & 14.63846 \\
\hline 12 & L & 10 & 0 & 14.63846 \\
\hline 13 & M & 3 & 7 & 7.638462 \\
\hline Total & & & 20.1 & \\
\hline
\end{tabular}

TABLE 2. THE THIRD ROUND OF THE GAME[1]

\begin{tabular}{|c|c|c|c|l|}
\hline Round 2 & Code name & Private & Public & Income \\
\hline 1 & $\mathrm{~A}$ & 8 & 2 & 10.53846 \\
\hline 2 & $\mathrm{~B}$ & 9 & 1 & 11.53846 \\
\hline 3 & $\mathrm{C}$ & 9 & 1 & 11.53846 \\
\hline 4 & $\mathrm{D}$ & 10 & 0 & 12.53846 \\
\hline 5 & $\mathrm{E}$ & 10 & 0 & 12.53846 \\
\hline 6 & $\mathrm{~F}$ & 6 & 4 & 8.538462 \\
\hline 7 & $\mathrm{G}$ & 9.5 & 0.5 & 12.03846 \\
\hline 8 & $\mathrm{H}$ & 9.5 & 0.5 & 12.03846 \\
\hline 9 & $\mathrm{I}$ & 10 & 0 & 12.53846 \\
\hline 10 & $\mathrm{~J}$ & 10 & 0 & 12.53846 \\
\hline 11 & $\mathrm{~K}$ & 10 & 0 & 12.53846 \\
\hline 12 & $\mathrm{~L}$ & 10 & 0 & 12.53846 \\
\hline 13 & $\mathrm{M}$ & 8 & 2 & 12.53846 \\
\hline Total & & & 11 & \\
\hline
\end{tabular}

\subsection{The Third Round}

In this round, there's 13 yuan in the public account. From table 3 , ten of the thirteen participants have chosen zero investment. Participants who have invested in the first two rounds have lost their trust in the collective and have chosen zero investment.

TABLE 3. THE THIRD ROUND OF THE GAME[1]

\begin{tabular}{|l|l|l|l|l|}
\hline Round 3 & Code name & Private & Public & Income \\
\hline 1 & A & 10 & 0 & 13 \\
\hline 2 & B & 10 & 0 & 13 \\
\hline 3 & C & 0 & 10 & 3 \\
\hline 4 & D & 10 & 0 & 13 \\
\hline 5 & E & 10 & 0 & 13 \\
\hline 6 & F & 8 & 2 & 11 \\
\hline 7 & G & 10 & 0 & 13 \\
\hline 8 & H & 10 & 0 & 13 \\
\hline 9 & I & 10 & 0 & 13 \\
\hline
\end{tabular}

\begin{tabular}{|l|l|l|l|l|}
\hline 10 & $\mathrm{~J}$ & 10 & 0 & 13 \\
\hline 11 & $\mathrm{~K}$ & 10 & 0 & 13 \\
\hline 12 & $\mathrm{~L}$ & 10 & 0 & 13 \\
\hline 13 & $\mathrm{M}$ & 9 & 1 & 12 \\
\hline Total & & & 13 & \\
\hline
\end{tabular}

The reason why the total amount is so high is that an honest man believed the author's proposal and put all his money into the public account.

At last, I summarized the total income of the three rounds of games. The five participants with zero investment from the beginning were the top five.

\section{Discussion}

Paying nothing to the group, commonly known as eating free food, is a vicious circle and is very common in society [4]. The free ride in society does not necessarily have to be invested with capital, it can also be hard work or spending time on performance. Some people are passive in this cycle. When the ability of the people around him is better than that of himself. It doesn't make any difference whether he try hard or not. He can't be outstanding without free ride. Some people want to take the free ride from the first step into the company. If there are no risks for them to take, why don't they enjoy themselves ?Some people are willing to pay effort at the beginning, but when they see that others do not pay much and they can get higher profits than they do... As time goes by, their mentality will collapse, then they will get the free ride. Finally the cycle is done.

Imagine a man is working hard with some free riders to improve the company's efficiency, and then the results are shared equally by all of the people, and everyone is equally allocated the same bonus. What should teacher this man do?

First choice: Stop paying effort and get a free ride with everyone (which is consistent with most people's experimental results). The end result is that everyone starts to free-riding, and the company is no longer productive and goes bankrupt.

Second Choice: Force the company to replace the free riders and work together to double the output and improve the average income of each person (some participants called on everyone to invest 10 yuan, and only one person believed him).

Third Choice: It is suggested that the company's boss should increase the proportion of individual incentives (which may require additional costs).

Fourth Choice: Change to another company (seems to be the most convenient).

\section{Conclusion}

People sometimes make their own decisions under the constraints of becoming a member of a team or organization.

The team members can be able to promote the collaborative actions of the team members based on the dedication level of the team members to other team 
members and improve the peace of mind of the team members. On the contrary, the friends can be based on the team members to master other team members. To improve. Another finding is that the actual effect of gifts has improved the level of dedication, especially in a collaborative atmosphere, but not in a collaborative atmosphere.

In the article, four levels of personality traits are studied: the preference for market competition, the preference for risk, the passion for profit and the trust in others. Free-riders tend to feel that market competition is available. This was created under the no-reward standard, but not under the reward standard. Because of the former situation, many people have become standard partners. The risk-preventing person can reduce his level of dedication under a large reward standard, and is worried about being used by free-riders. Pursuing perfect profitability, I tend to free ride without knowing other people and group members. Ultimately, people who expect less and less rewards from others tend to collaborate. This is the key way that culture and art endanger the high efficiency of economic development.

\section{ACKNOWLEDGMENT}

First and foremost, I would like to show my deepest gratitude to my teachers and professors in my university, who have provided me with valuable guidance in every stage of the writing of this thesis. Further, I would like to thank all my friends and roommates for their encouragement and support. Without all their enlightening instruction and impressive kindness, I could not have completed my thesis.

\section{REFERENCE}

1. Baik. K. H. ( 2008)," ContestsWith Group-Specific Public-Good Prizes ,"Social Choice and Welfare 30 ,pp.103-117.

2. Baik K .H .,Kim I-G ,Na (2001)," Biddingfor a Group-Specific Public Good Prize ,"Journal of Public Economics 82 ,pp .415-429.

3. Marwell ,G .,Ames ,R .,(1981)," Economists Free Ride ,Does Anyone Else ?Experiments on the Provision of Public Goods ,IV ,"Journal of Public Economics 15 ,pp .295-310.

4. Zuo, Zhou. Rotating group representatives and group members' requests in repeated public goods game. 2020, 52(40):4351-4365.

5. Qiao Chen, Tong Chen. Group rewarding can promote cooperation and save costs in public goods games. 2020, 2020(7) 